\title{
Patrón en panal de abeja
}

\author{
Honeycombing
}

Ana Cristina Manzano D., MD(1); Olga Milena García, MD(2); Carlos Celis Preciado, MD(3)

(1)Radióloga, Departamento de Radiología, Hospital Universitario San Ignacio. Pontificia Universidad Javeriana. Bogotá, Colombia.

${ }^{(2)}$ Internista, Fellow de Neumología, Unidad de Neumología, Hospital Universitario San Ignacio. Pontificia Universidad Javeriana. Bogotá, Colombia.

${ }^{(3)}$ Internista, Neumólogo, Unidad de Neumología, Hospital Universitario San Ignacio. Pontificia Universidad Javeriana. Bogotá, Colombia.

Correspondencia:Ana Cristina Manzano. Correo electrónico: acmanzano@javeriana. edu.co

Recibido: 03-03-2013. Aceptado: 25-04-2013.
En su Glosario de Términos de Radiología Torácica, la Sociedad Fleischner define este hallazgo en la radiografía de tórax como sombras anulares entre 3 y $10 \mathrm{~mm}$ de diámetro con paredes bien definidas de 1 a $3 \mathrm{~mm}$ de espesor (1).

En la tomografía de tórax de alta resolución (TCAR), su apariencia es la de quistes agrupados, usualmente de localización subpleural, con diámetros similares entre 3 a $10 \mathrm{~mm}$ (ocasionalmente pueden llegar hasta $2,5 \mathrm{~cm}$ ) y de paredes bien definidas. Su hallazgo indica fibrosis pulmonar establecida (1). Los quistes suelen alinearse en hileras relativamente ordenadas, de periferia a centro, y comparten paredes. Se asocian con distorsión de la arquitectura del pulmón y bronquiectasias y bronquiolectasias por tracción (figura).

El patrón en panal de abejas fue descrito en 1949 por Oswald y Parkinson (2), y en 1988 Fraser y colaboradores (3) correlacionaron dicho hallazgo con la gravedad de la patología pulmonar implicando un estadio terminal. Desde los años 90 se ha hecho énfasis en que el patrón en panal de abeja es un sello distintivo de fibrosis pulmonar (4) y su presencia es necesaria para el diagnóstico de patrón de neumonía intersticial usual, según los criterios recientes de ATS-ERS-JRS-ALAT (5).

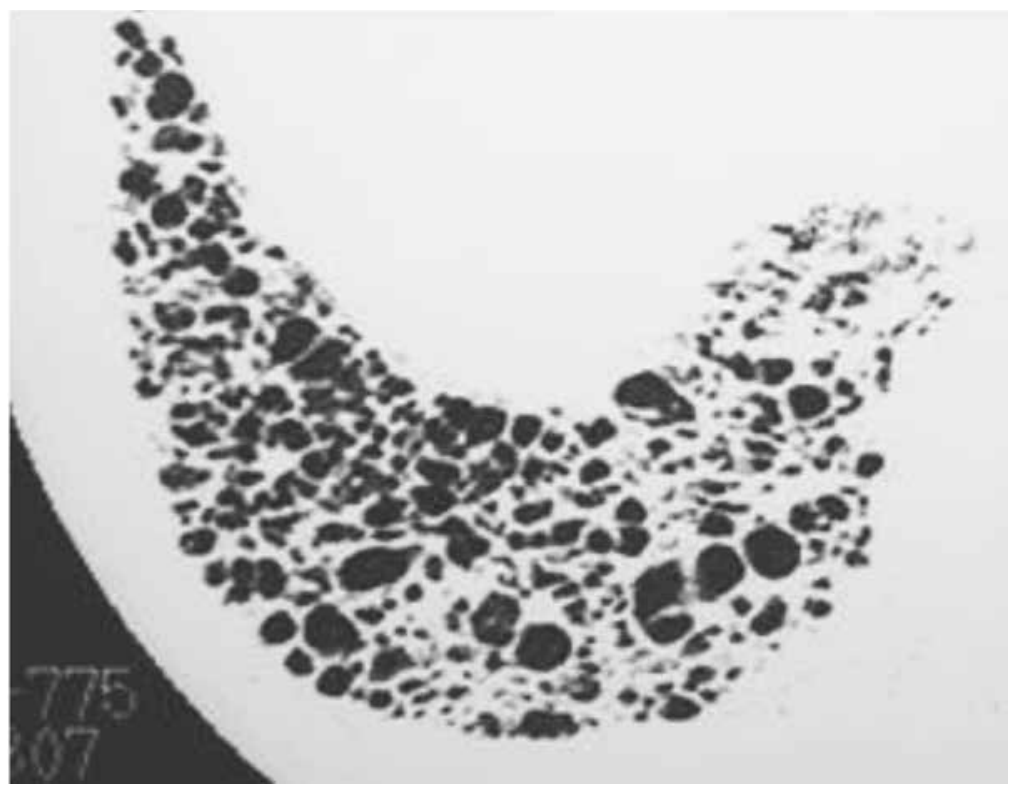

Figura. Patrón en panal de abeja en la TCAR. Múltiples quistes alineados, de pared compartida reemplazando el parénquima pulmonar normal. 
Desde el punto de vista histológico, el panal de abejas representa la destrucción y fibrosis del tejido pulmonar que contiene numerosos quistes del espacio aéreo con paredes fibrosas gruesas, con pérdida completa de la arquitectura acinar. Los quistes varían en tamaño y están revestidos por epitelio bronquial metaplásico (4).

Tanto en fibrosis pulmonar idiopática como en enfermedad intersticial asociada con enfermedades del tejido conectivo, la extensión del panal de abejas es un factor basal e independiente de pronóstico (mortalidad), junto con la disnea y la capacidad de difusión de monóxido de carbono $(4,6)$.

\section{Bibliografía}

1. Fleishnner Society: Glossary of terms for thoracic imaging. Radiology 2008;46:697-722.

2. Oswald N, Parkinson T. Honeycomb lungs. QJM 1949;18:1-20.

3. Frase RG, Pare JAP, Pare PD, Fraser RS, Genereux GP. Diagnosis of Diseases of the Chest, vol. 1, 3rd. ed. Philadelphia, PA: W.B. Saunders; 1988. p. 552-65.

4. Johkoh T, Sakai F. Honeycombing on CT; its definition, pathologic correlation, and future direction of its diagnosis. Eur J Radiol. 2014;83:2731 .

5. Raghu G, Harold R et al.. An Official ATS/ERS/JRS/ALAT Statement: Idiopathic Pulmonary Fibrosis: Evidence-based Guidelines for Diagnosis and Management. Am J Respir Crit Care Med. 2011;183:788-824.

6. Walsh SL, Sverzellati N, Devaraj A, Keir GJ, Wells AU, Hansell DM. Connective tissue disease related fibrotic lung disease: high resolution computed tomographic and pulmonary function indices as prognostic determinants. Thorax. 2014;69:216-22. 